http://dx.doi.org/10.30681/23588403v12i012035

\title{
APAGAMENTO DO PLURAL NA CONCORDÂNCIA NOMINAL DO FALANTE DE MACEIÓ
}

Data de recebimento: $29 / 10 / 2017$

Aceite: 04/12/2017

Neilton Farias Lins (UFAL) ${ }^{1}$

RESUMO: Esta pesquisa busca antes de tudo, fazer uma investigação do apagamento do plural na Concordância Nominal no falar dos maceioenses. Para tanto, foi necessária uma pesquisa séria e cuidadosa de falantes da comunidade linguística de Maceió. Alguns fatores foram tomados como determinantes nessa pesquisa, tais como variáveis dependentes e independentes, que se relacionaram ao falante e a fala desta comunidade específica. Para tanto, tal pesquisa toma como trabalhos basilares, importantes investigações, dentre elas se destacam os trabalhos pioneiros de Scherre (1988), Scherre (1994), Scherre (1998) Scherre e Naro (2007), Bortoni-Ricardo (2009) outras pesquisas, de igual modo, ganham lugar nessa discussão, embora que desde já, se reconhece a incapacidade de se deter a todos os trabalhos que se propuseram explicitar a temática que ganha destaque nesse artigo.

PALAVRAS-CHAVE: Variável, Concordância Nominal, Plural.

ABSTRACT: This research seeks first of all, the investigation of erasure in the plural in speaking of Concordance Nominal maceioenses. To do that, we needed a serious and careful research speakers linguistic community Maceio. Some factors were taken as determinants in this research, such as dependent and independent variables that related to the speaker and speech of this particular community. To this end, research such takes as fundamental work, important investigations, among which stand out the pioneering work of Scherre (1988), Scherre (1994), Scherre (1998) Scherre and Naro (2007), Bortoni-Ricardo (2009) other research likewise, earn place in this discussion, although it already recognizes the inability to stop all work that proposed to clarify the issue that is highlighted in this article.

KEYWORDS: Variable, Nominal Agreement, Plural.

\section{INTRODUÇÃO}

Ao tratar da respectiva temática Bortoni-Ricardo (2009, p.88), enfatiza que é necessário fazer uma distinção entre o /s/ pós-vocálico e o /s/ que não é morfema. Essa autora argumenta que o /s/ pós-vocálico, em finais de palavras, tendencialmente são mais apagados

\footnotetext{
${ }^{1}$ Mestre em Linguística pela UFAL, Professor de Língua Português de Instituto Federal de Alagoas - Santana do Ipanema - AL.
} 
do que os /s/ que são partes das palavras e não um acréscimo de marca de pluralização. Como é o caso das palavras "pires" e "lápis", que dificilmente as pessoas apagam o respectivo /s/. Essa autora diz que:

...convém fazer a distinção entre o /s/ pós-vocálico que é morfema de plural (ou seja, é o elemento que contém a marca de plural) e o /s/ que não é morfema de plural. Vejamos exemplos do /s/ como marca de plural: aluno $+\mathrm{s}$, lâmpada $+\mathrm{s}$, coelho $+\mathrm{s}$. Vejamos agora palavras monomorfêmicas (formadas por um único morfema em que o /s/ é parte do morfema lexical: lápis, pires, Paris, atrás, etc.

Para tratar da questão inerente ao que se tem proposto, é preciso antes de tudo reconhecer que a língua se constitui especificamente de dois aspectos distintos: a oralidade e a escrita. No que se refere à modalidade escrita, o sujeito linguístico se esforça em fazer usos das normas preestabelecidas pela Gramática Normativa ou norma "culta", conquanto, isso nem sempre acontece da maneira que se tem idealizado. No que se refere à fala, é possível constar que mesmo quando houver um elevado índice de monitoramento, na maioria das vezes, ocorre de maneira mais irrefletida.

\section{O APAGAMENTO DO PLURAL NA CONCORDÂNCIA NOMINAL DO MACEIOENSE.}

As discussões que nessa pesquisa serão levantadas tomam como fundamentais as teorias da Sociolinguística Quantitativa. A Sociolinguística tem sido definida em sentido lato como a ciência que tem pleiteado como objeto de pesquisas as variações e mudanças linguísticas e os respectivos fatores que influenciam tais ocorrências em uma língua.

Além do exposto convém destacar que a referida pesquisa não tem pretensão de se deter nas questões relacionadas à ideia de variedade "certa" ou "errada", visto que ao se tratar da fala, independentemente de que classe social, faixa etária, nível de escolarização, gênero esse falante pertença, o uso que faz da língua não podem ser julgadas como "certo" ou "errado", "feio" ou "bonito", "culto" ou "coloquial", vai além disso, trate-se necessariamente, de variações "estigmatizadas" ou "prestigiadas". Nesse caso, sim, os fatores extralinguísticos influenciam em sua valoração ou não.

No decorrer da implementação desta pesquisa, especificamente na coleta de dados e transcrição de falas, mesmo que de forma empíricas, constatou-se algo capaz de chamar a 
atenção no que se refere ao uso da variável da concordância nominal, especificamente, no que diz respeito às questões relacionadas à marcação do plural nos sintagmas nominais. O que se constatou foi a uma tendência dos falantes maceioenses de eliminar na fala, as marcas redundantes de plural, por exemplo: “As pessoa Ø”, "muitas coisa errada $\varnothing " 2$. O plural recebe marcação, em geral, apenas no primeiro elemento do sintagma nominal. Logo, é possível inferir que na fala é usada uma construção sintática distinta do que se tem preestabelecida pela norma padrão.

Tal constatação, aguçou-nos o interesse de pesquisar o apagamento do plural na concordância nominal, no falar dos habitantes de Maceió (AL), ressaltando a determinação de alguns grupos de fatores extralinguísticos ou variações independentes na fala espontânea, fatores tais como: gênero, idade; e de grupos de fatores linguísticos ou variáveis dependentes, como: a saliência fônica, distância de elementos no sintagma nominal. O tipo de sintagma nominal utilizado como dado de análise foi com dois até quatro elementos, tais como: "das brincadeiras", "todas as brincadeiras sadias"3, etc.

As hipóteses basilares desta pesquisa tomaram como fundamentação os estudos sociolinguísticos, foram as seguintes:

a) A eliminação das marcas de plural, geralmente, acontece apenas no determinante ou em elementos mais à esquerda do sintagma nominal, na primeira casa, (SCHERRE 1978; 1988). Ex.: “As meninaØ”;

b) Elementos mais salientes favorecem as marcas de plural explícitas (SCHERRE 1978; 1988). Ex: "os meses"4;

d) Quanto mais jovens, mais utiliza a forma considerada padrão, isso, talvez influenciado pelo mercado e trabalho e o acesso à escolarização.

e) As mulheres fazem mais a concordância nominal padrão.

Ao tratar da saliência fônica em estudos de concordância verbal Scherre \& Naro (1998) verificam que o aumento da distinção do material fônico na oposição singular/plural dos verbos analisados aumenta as chances concordância verbal, mencionam ainda que, a

\footnotetext{
${ }^{2}$ Fragmento de fala transcrita do informante RMI, pertencente ao Banco de Dados construídos a partir de entrevistas realizadas por alunos de mestrado e doutorado do PPGLL-UFAL, na disciplina Teoria da Variação Linguística sobre a responsabilidade do Prof. Dr. Alan Jardel de Oliveira

${ }^{3}$ Fragmento de fala transcrita do informante NFJ, pertencente ao Banco de Dados já mencionado.

${ }^{4}$ Embora se reconheça a consistência dessa hipótese, em nossa pesquisa não foi considerado relevante o resultado obtido por meio do GoldVarb nas transcrições das entrevistas feitas de falantes maceioenses.
} 
saliência fônica aumenta as chances da variante explícita de plural. Esse último teórico em Naro (1981) argumenta que, "a hierarquia da saliência deve ser estabelecida em função de dois critérios: (1) presença ou ausência de acento na desinência e (2) quantidade de material fônico que diferencia a forma singular da forma do plural”.

É preciso considerar que, quanto mais salientes os itens, mais favorecem a presença de marcas explícitas nos elementos nominais dos sintagmas nominais. Os menos salientes ou regulares, menos favorecem a presença de marcas explícitas.

A análise da posição da variável nos dados dos sintagmas nominais segue o seguinte acontecimento: a posição à esquerda - a posição de proeminência tópica - favorece mais marcas explícitas de plural do que a posição à direita, independentemente do nível de escolarização dos falantes. Elementos não nucleares à esquerda do núcleo favorecem marcas explícitas; elementos não nucleares à direita do nome desfavorecem-nas.

\section{PROCEDIMENTOS METODOLÓGICOS}

A pesquisa foi efetuada a partir de um banco de dados constituído pela língua falada em Maceió - AL, obtido por meio de entrevista ${ }^{5}$, com 18 falantes da respectiva cidade, 15 minutos de gravação de cada informante, cuja a faixa etária compreende: entre 18 e 30 anos, 40 e 55 anos e acima de 65 anos, dividindo o número de informantes entre masculinos e femininos, ainda assim, os respectivos informantes se enquadram nos diversos níveis de escolaridade $^{6}$. Tais entrevistas foram coletadas no ano de 2014, tomando como princípios basilares, sobretudo, a metodologia de pesquisa e de coleta de dados da Sociolinguística Variacionista.

Na busca de verificar se, no português popular, o fenômeno do apagamento do plural na concordância nominal na cidade de Maceió - AL, caracteriza-se como variação estável ou tendência da mudança, nesse trabalho, foram quantificadas as ocorrências selecionadas na fala de 18 informantes (18/65 anos), num total de 645 ocorrências de Concordância Nominal na fala dos informantes maceioenses, utilizando o programa de quantificação estatística Goldvarb 2001. Apesar de um considerável número de ocorrências, assumimos que os resultados ainda não são conclusivos, mas apontam a direção a ser seguida e pontos que deveriam ser refletidos.

\footnotetext{
5 As respectivas entrevistas fazem parte do projeto Portal (Português alagoano/CNPq) que está sendo desenvolvido pelo professor Alan Jardel de Oliveira - PPGLL - UFAL

${ }^{6} \mathrm{O}$ fator escolaridade nessa pesquisa não foi considerado como elemento de análise.
} 
Para rodada inicial do Goldvarb, os falantes compreendem entre 18 e 30 anos, 40 e 55 anos e acima de 65 anos - residentes em diversos bairros da cidade de Maceió - AL, foram selecionados considerando os critérios sociais:

\section{I - gênero:}

A) homens - 09 informantes

B) mulheres - 09 informantes

\section{II - idade:}

A) faixa I - 18 aos 30 anos - 06 informantes

B) faixa II - 40 aos 55 anos - 06 informantes

C) faixa III - acima de 65 anos - 06 informantes

Para tanto a entrevista tomou como princípio norteador o seguinte roteiro de perguntas, elencado pelo professor Alan Jardel de Oliveira no blog ${ }^{7}$ da disciplina Teoria da Variação Linguística - Programa de Pós-Graduação de Letras e Linguística da Universidade Federal de Alagoas:

1) Como foi a sua infância em Maceió? Conte algum fato importante pra você.

2) Que tipo de brincadeiras você fazia na infância? Conte um pouco sobre elas?

3) Conte algumas lembranças da sua infância na escola.

4) Do que você sente falta na sua infância? Por quê?

5) Como era a cidade de Maceió na sua infância? O que mudou? Piorou o melhorou?

6) Qual a sua opinião sobre a violência em Maceió? O que poderia ser feito para diminuir a violência na cidade?

7) Conte uma história de amor sua ou de pessoas próximas a você.

8) Como você se imagina daqui a cinco anos?

Essas entrevistas foram realizadas pelos alunos da disciplina mencionada, em que cada aluno participante ficou responsável por entrevistar uma pessoa, depois fazer transcrição da fala no ELAN, seguindo as normas da Sociolinguística e a norma padrão, a fim de facilitar a criação do banco de dados.

Quanto aos critérios e equipamentos utilizados para compor o banco de dados foi diversificado, tais como aparelho de MP4, gravadores, celulares, dentre outros, para isso considerando o cuidado que se deve ter com o "paradoxo do observador", nesse aspecto, fazendo uso de estratégias como perguntas com palavreado simples e do dia a dia dos

\footnotetext{
${ }^{7}$ http://ppglltvl.blogspot.com.br/2014_04_01_archive.html.
} 
informantes, tais como mencionadas anteriormente, sendo para isso, realizadas por meio de um protocolo de perguntas pré-formuladas, sem o imperativo de dar seguimento nas perguntas, com isso, lembrando que a finalidade é o de levar os falantes se envolverem em sua fala, para obtenção do vernáculo por eles utilizados.

De posse das entrevistas, deu-se início as transcrições dos dados dos falantes maceioenses, seguidamente, procederam-se a marcação das sentenças em que se podia constatar o apagamento ou a conservação do plural na concordância nominal, e seguiu-se, então, à análise e comparação dos dados. Para a análise dos dados foi usado o Goldvarb, versão 2001.

Embora essa pesquisa tenha contemplado elementos linguísticos, tais como, distância dos elementos nos sintagmas nominais e saliência fônica, o foco de análise concentrou-se no comportamento da variável extralinguística faixa etária e fatores de gênero, uma vez que as leituras feitas pelo Goldvarb não atribuíram relevância às variáveis dependentes, na realização da regra de concordância de número plural no $\mathrm{SN}$, quiçá isso se explique pela quantidade dados. Os corpora produzidos através da apreciação da concordância nominal referencialmente às variáveis independentes foram investigados e interpretados à luz das teorias Sociolinguística laboviana.

Para a inclusão/exclusão de dados de análise foi utilizada nesse estudo, o que preconiza Scherre (1988). Nesse sentido, convinha necessariamente, que houvesse no mínimo a presença de um elemento indicador da marca pluralização, nesse aspecto, dados tais como o enunciado: "essa nova tecnologia", não existia emprego de nenhuma marca de pluralidade no sintagma, nesse aspecto, não havendo o que se explicar, foram descartados tais enunciações, entretanto, dados como: “essas nova tecnologias", "essa nova tecnologias”, “essas novas tecnologia" e "essa nova tecnologia", foram consideráveis como dados para análise.

\section{ANÁLISE DOS DADOS}

No quadro geral, o resultado quanto à observação da concordância nominal na cidade de Maceió - AL, revelou o significativo índice de não aplicação à regra geral de concordância.

\footnotetext{
${ }^{8}$ Informante AFA, pertencente ao Banco de Dados construídos a partir de entrevistas realizadas por alunos de mestrado e doutorado do PPGLL-UFAL, na disciplina Teoria da Variação Linguística sobre a responsabilidade do Prof. Dr. Alan Jardel de Oliveira
} 


\begin{tabular}{lcc}
\hline $\begin{array}{l}\text { Concordância }(\tilde{\mathbf{n}}) \\
\text { realizada }\end{array}$ & Ocorrência & Frequência \\
\hline $\begin{array}{l}\text { (+) Não Apagamento do } \\
\text { plural } \\
\text { (-) Apagamento do plural }\end{array}$ & $256 / 645$ & 39.7 \\
\hline & $389 / 645$ & 60.3 \\
\hline & & Tabela de $N^{o} 01$
\end{tabular}

Os fatores que tomamos como determinantes foram: extralinguísticos ou variáveis independentes - a idade e o gênero, na intenção de se obter um melhor conhecimento sociocultural da espaço investigada, e linguísticos ou variáveis dependentes - a saliência fônica ${ }^{9}$, que fora analisada em duas possibilidade de realizações, maior saliência e menor saliência; segunda variável dependente é a posição de distanciamento no sintagma nominal, essa variável foi analisada em duas possibilidades de realizações, distância zero, ou seja, elementos próximos no sintagma nominal, distância um, acontece quando o determinante está separado por uma ou mais palavra do termo com que deve ${ }^{10}$ estabelecer a concordância. Os dados de elocução livre analisados mostram que os falantes do município investigado utilizam mais a não-concordância, variante considerada não-padrão e inovadora (60\%). Veja-se na tabela de análise de dados obtida por meio do Goldvarb 2001:

Non-

Group Apps apps Total \%

\begin{tabular}{|c|c|c|c|}
\hline \multicolumn{4}{|l|}{$1(2)$} \\
\hline $\mathrm{F} \quad \mathrm{N}$ & 225 & 117 & 34253 \\
\hline$\%$ & 65 & 34 & \\
\hline $\mathrm{MN}$ & 164 & 139 & 30346 \\
\hline$\%$ & 54 & 45 & \\
\hline Total N & 389 & 256 & 645 \\
\hline$\%$ & 60 & 39 & \\
\hline
\end{tabular}

A análise de grupos de outros fatores condicionantes realizada nas pesquisas sociolinguísticas, como é o caso da distância do elemento no sintagma nomina, tem demonstrado de forma geral que, quanto mais distante for o elemento no sintagma nominal,

\footnotetext{
${ }^{9}$ Saliência fônica compreende a distinção sonora na pluralização de um termo. Lemle \& Naro (1977) diz que: quanto menor a distinção, maior a tendência em neutralizar a oposição e prevalecer o uso de apenas uma das formas.

${ }^{10}$ A escolha metodológica escolhida se deu pela mínima quantidade de dados em uma terceira distância, nesse aspecto, juntou-se os dados de uma primeira, segunda e terceira posição em relação ao determinante, formando os elementos relacionados à maior distância do elemento determinante.
} 
menor será a concordância no plural, ou seu apagamento, no falar maceioense esse fator tem se confirmado, uma vez que a distância zero ${ }^{11}$ do determinante, o qual exige que a concordância seja feita com ele, tem influenciado na concordância do sintagma nominal, levando o falante manter a norma padrão, enquanto que uma distância maior tem favorecido para que os falantes maceioenses apaguem o plural no sintagma nominal. Veja-se a tabela ${ }^{12}$ do Goldvarb 2001.

\begin{tabular}{ccccc}
\multicolumn{6}{c}{ Non- } & \\
Group & Apps & apps & Total \% \\
3(4) & & & & \\
D & 219 & 328 & 547 & 84.8 \\
$\%$ & 40.0 & 60.0 & & \\
d & 37 & 61 & 98 & 15.2 \\
$\%$ & 37.8 & 62.2 & & \\
Total N & 256 & 389 & 645 \\
$\%$ & 39.7 & 60.3 &
\end{tabular}

Da mesma forma, constatou-se que a saliência fônica mostrou um resultado semelhante ao que se esperava nessa pesquisa, uma vez que a mesma vem corroborar o que as pesquisas da Sociolinguística de modo geral têm demonstrado que, quanto maior a saliência, maior será o favorecimento para não aplicação da concordância. Em nossa pesquisa isso tem sido constatado, apresentando o percentual de 40,7\% de aplicação da regra para maior saliência e de $34,3 \%$ de aplicação da regra para uma menor saliência. Como se percebe na tabela a seguir:

\footnotetext{
${ }^{11}$ A distância zero do determinante e a palavra que a ele se refere é referenciada pela letra "d", a distância maior pela letra " $D$ ", a saliência fônica maior pela letra "D" e a saliência menor pela letra "d".

${ }^{12}$ As tabelas do Goldvarb de distância do elemento no sintagma nominal e saliência fônica são apresentadas como uma tentativa de suprir a necessidade dos dados de peso relativo, uma vez que o respectivo programa não determinou tais fatores como relevantes.
} 


\begin{tabular}{|c|c|c|c|}
\hline \multicolumn{4}{|c|}{ Non- } \\
\hline Group & Apps & apps & Total \% \\
\hline \multicolumn{4}{|l|}{$4(5)$} \\
\hline & 221 & 322 & 54384.2 \\
\hline & 40.7 & 59.3 & \\
\hline \multirow[t]{2}{*}{$\mathrm{S}$} & 35 & 67 & 10215.8 \\
\hline & 34.3 & 65.7 & \\
\hline \multirow{2}{*}{$\begin{array}{c}\text { Total N } \\
\%\end{array}$} & 256 & 389 & 645 \\
\hline & 39.7 & 60.3 & \\
\hline
\end{tabular}

Quanto aos fatores relacionados ao gênero e idade, ficou comprovado que as mulheres tendencialmente usam mais norma padrão, o que de forma geral corrobora o que as pesquisas sociolinguísticas têm apontado, uma vez que nessa investigação é demonstrado que, enquanto os homens fazem $54, \%$ da concordância, as mulheres fazem $65 \%$.

\begin{tabular}{lllll}
\hline Fator & Ocorrência & Total & Frequência & Peso relativo \\
\hline Feminino & $117 / 225$ & 342 & 53,0 & 0.410 \\
Masculino & $139 / 164$ & 303 & 45,9 & 0.601 \\
\hline
\end{tabular}

Tabela de No02 de Peso Relativo de Aplicação do Apagamento do Plural

Considerando a quantidade dos dados obtidos é possível inferir, primeiro do que tudo que, o masculino apaga mais o plural que o feminino, isso por considerar o peso relativo do masculino é de 0.601 e do gênero feminino: 0.410. Para se chegar a um resultado categórico é preciso considerar o peso relativo dessa ocorrência. Antes de se chegar a um resultado, cabe fazer uma análise mais detalhada de outras variáveis que o Goldvarb determinou como relevante para essa pesquisa.

A seguir, apresentaremos os resultados e suas respectivas tabelas de fatores, bem como peso relativos da frequência encontrada para cara grupo de fatores e quais variáveis se mostraram mais relevantes na análise dos dados. 


\section{Variáveis independentes ou extralinguísticas.}

Foi possível quantificar a frequência de 02 variáveis sociais: a) de gênero; b) de faixa etária.

\section{Variável independente Gênero}

Em relação a variável de "gênero", estudos que adotam como base o português dito popular têm evidenciado a pressuposição de que, ante a performance dos papeis sociais (WOLFRAM,1969), conjecturava "maior consciência feminina do status social das formas linguísticas", o que poderia fazer com que as mulheres proporcionassem um índice mais elevado de aplicação à norma.

Em nossa análise, verificamos que a hipótese de WOLFRAM (1969), no caso do português da cidade Maceió - AL, tem sido comprovada, embora tal hipótese tem sido questionada em outras pesquisas, cuja aplicação da norma tem sido recorrente em sua maioria na variável do fator gênero masculino, como é o caso por exemplo, da pesquisa de (SILVA et al, 2012). Naquela respectiva pesquisa, observou-se que o gênero masculino utiliza a variação próxima da norma. Embora os autores (Ibdem, p.4) assumam que "a baixa estatística observada na diferenciação dos dois grupos ainda não se constitui suficiente para uma teoria mais contundente". Nossos dados apresentam a seguinte a tabela de apagamento do plural no sintagma nominal e os pesos relativos em nossa pesquisa:

\begin{tabular}{|c|c|c|c|c|}
\hline Fator & $\overline{\text { Ocorrência }}$ & $\overline{\text { Total }}$ & $\overline{\text { Frequência }}$ & $\begin{array}{l}\text { Peso } \\
\text { relativo }\end{array}$ \\
\hline Feminino & $117 / 225$ & 342 & 53,0 & 0.410 \\
\hline Masculino & $139 / 164$ & 303 & 45,9 & 0.601 \\
\hline
\end{tabular}

não quer se alegar nem de longe, de perto ou qualquer outra perspectiva que seguimos fielmente o que propõe WOLFRAM (1969), embora nossa pesquisa queira corroborar com o pensamento wolframiano de que haja uma "consciência feminina" que de alguma forma leva a mulher a cumprir a norma padrão bem mais que os homens. Isso visto de forma contrária na pesquisa desenvolvida por Carvalho (1997), em que o respectivo autor fez um estudo sobre a concordância de número no sintagma nominal na fala urbana da cidade de Rio Branco. Esse 
pesquisador enfatiza que os homens na fala da cidade em pesquisada, fazem mais a concordância nominal do que as mulheres. Vejamos a tabela de aplicação da regra da concordância nominal por ele apresentada:

\begin{tabular}{lllll}
\hline Fator & Ocorrência & Total & $\overline{\text { Frequência }}$ & $\begin{array}{l}\text { Peso } \\
\text { relativo }\end{array}$ \\
\hline Feminino & 1057 & 1664 & 64 & 0.42 \\
Masculino & 963 & 1334 & 72 & 0.60 \\
\hline \multicolumn{5}{c}{ Tabela de $N^{\boldsymbol{o}}$ O2 de Carvalho (1997) }
\end{tabular}

Segundo o respectivo estudioso, por meio dessa tabela é possível inferir que os homens são tendentes a se aproximar mais da norma culta que as mulheres. Contudo, no que diz respeito às variedades de gênero, não se constitui algo relativamente simples de se construir juízo de valor. Razão que nos leva a fazermos citação das contribuições levantadas por Scherre (1978), a qual toma como respaldo as observações elencadas por Labov (2008), a respeito da declaração feita por alguns pesquisadores, na acepção de que as mulheres fazem mais uso da norma prestigiada que os homens. A pesquisadora enfatiza que Labov avalia como "um erro adotar como princípio geral que as mulheres conduzem o curso da mudança linguística, pois há também evidências de influências exercidas pelos homens". (cf SCHERRE, 1978:115).

Embora anterior Labov (2008, p. 347) tenha levantado a hipótese de que os pais exercem de forma geral uma influência muito forte sobre a língua da criança, e a mãe (mulher) de forma especial exerce um poder ainda maior, isso por que segundo esse autor "as mulheres conversam mais do que os homens com as criancinhas", dessa forma exercendo um poder maior de influência sobre tais crianças, sem contar que, se essas crianças passarem pelo período de alfabetização, que coincidentemente é também o período da aquisição da língua, tais crianças serão inseridas na língua materna por uma professora, raramente por um professor.

De forma geral corroboramos com o pensamento laboviano, para quem " $\mathrm{Na}$ fala monitorada, as mulheres usam menos formas estigmatizadas do que os homens (Labov 1966a: 288) e são mais sensíveis do que os homens ao padrão de prestigio...”, logo cabe salientar que as mulheres (0.410) que apresentaram um desempenho abaixo do que obtiveram os homens (0.601), demonstram, destarte, implicações compatibilizadas com que tem postulado Labov (2008). 
Nesse sentido, apreendemos que, de forma geral, o distinto desempenho linguístico entre homens e mulheres, falantes do dialeto maceioense, é quiçá ${ }^{13}$ explicado, devido os diferentes papéis sociais que eles ocupam na comunidade de Maceió.

\section{Variável independente Faixa Etária}

A análise da variável faixa etária é capaz de permitir ao pesquisador a percepção de prováveis mudanças linguísticas que estão em curso na comunidade em estudo, isso se dá por intermédio da verificação do que (Labov, 2008), chama de tempo aparente. Esse fenômeno acontece quando esta variável é identificada como uma distribuição curvilínea, tudo isso revela ao pesquisador que se está diante uma variação estável, ou mesmo, um estágio de clara transformação linguística consumada.

De outro modo, caso a variável faixa etária se caracterize uma distribuição inclinada, com o alto índice de acontecimento aquisitivo da regra de concordância na faixa etária mais nova, em nosso caso os jovens, e o maior índice de variação na faixa etária mais velha, os idosos, é possível inferir que a comunidade linguística está em fase de mudança em progresso, como bem enfatiza (Chambers \& Trugdil, 1998; Baxter, Lucchesi \& Guimarães, 1997). Apesar disso, cabe salientar que a variável faixa etária, sozinha, não é capaz de satisfazer a necessidade indicativa de uma mudança em progresso, de forma que é imperativo buscar a outros fatores sociais vinculado a ela, tais como o gênero sexual dos informantes, a escolarização e ainda, a camada social em que estão vinculados.

A pesquisa que temos desenvolvido corrobora com a possibilidade dessa segunda hipótese, embora é preciso esclarecer que os resultados não são conclusivos, visto que é possível crer numa mudança expressiva de índices se outros dados foram acrescentados.

As pesquisas têm sido unânimes em afirmar que, quantos mais jovens, mais marcam o plural na concordância nominal. Enquanto os jovens fazem 17,0 \% de não apagamento do plural os adultos $34,6 \%$ e os idosos fazem $65,9 \%$. Isso tem sido confirmado na investigação do falar maceioense. É o que confirmam os dados da tabela abaixo, obtida no Goldvarb 2001.

Non-

\footnotetext{
${ }^{13}$ Embora seja necessário enfatizar que essa afirmativa hipotética de explicação, pelos diferentes papeis que os informantes venham exercer na comunidade se dá exatamente, pelo fato de que não coube a essa pesquisa fazer uma análise das profissões exercidas pelos informantes dessa pesquisa. Mesmo que, no período da distribuição das entrevistas tenha-se cogitado a escolaridade do informante na pesquisa.
} 


\begin{tabular}{|c|c|c|c|}
\hline Group & Apps & s apps & Total \\
\hline \multicolumn{4}{|l|}{$2(3)$} \\
\hline \multirow[t]{2}{*}{ A $N$} & 85 & 161 & 24638.1 \\
\hline & 34.6 & 65.4 & \\
\hline \multirow{2}{*}{$\begin{array}{l}\mathrm{J} \\
\begin{array}{l}\mathrm{N} \\
\%\end{array}\end{array}$} & 32 & 156 & 18829.1 \\
\hline & 17.0 & 83.0 & \\
\hline \multirow{2}{*}{$\begin{array}{ll}\mathrm{I} & \mathrm{N} \\
\%\end{array}$} & 139 & 72 & 21132.7 \\
\hline & 65.9 & 34.1 & \\
\hline \multirow{2}{*}{ Total N } & 256 & 389 & 645 \\
\hline & 39.7 & 60.3 & \\
\hline
\end{tabular}

A tabela do peso relativo do fator faixa etária confirma que há uma tendência à mudança no uso da língua portuguesa na Cidade de Maceió, ou mudança em progresso, uma vez que, quanto mais idoso for o falante, mais tende a apagar o plural no sintagma nominal, e quanto mais jovem esse falante, mais tende a fazer o plural. É o que demonstra a tabela de peso relativo na faixa etária a seguir:

\begin{tabular}{lllll}
\hline Fator & Ocorrência & $\begin{array}{l}\text { Tota } \\
\text { l }\end{array}$ & Frequência & Peso relativo \\
\hline Adulto & $85 / 161$ & 246 & 34,6 & 0.444 \\
Jovem & $32 / 156$ & 188 & 17,0 & 0.247 \\
Idoso & $139 / 72$ & 211 & 65,9 & 0.778 \\
\hline \multicolumn{5}{c}{ Tabela de $N^{\circ} 3$ de apagamento do Plural no $S N$ - Faixa etária }
\end{tabular}

É importante frisar que o fator faixa etária se constitui um dos mais importantes fatores de análise sociolinguística, uma vez que é relativamente impossível para um pesquisador acompanhar anos a fio o processo evolutivo de uma variante em uma comunidade, sendo de certa forma, possível obtenção da mesma dimensão na investigação das transformações da língua, em uma comunidade, por meio da observação linguística de distintas faixas etárias.

Conforme Monteiro (2000) tal perspectiva é definida como tempo aparente. Apesar de uma possível análise nessa perspectiva, cabe salientar que um resultado mais contundente se dá mui especialmente, considerando uma análise em tempo real, visto que por meio desta perspectiva é que se pode realmente esclarecer se se trata de uma mudança linguística ou se o acontecimento linguístico incide apenas em uma variação inerente à graduação etária. $\mathrm{O}$ respectivo autor mencionado corrobora na importância de que, é preciso atentar para o fato de que toda mudança pressupõe variação, mas nem toda variação representa mudança. 
Nesse contexto, cabe a insistência no que advertiu Labov (1994, apud MONTEIRO, 2000), para quem as variações no fator faixa etária podem não significar respectivamente uma mudança linguística na comunidade de forma geral, todavia ser tão-somente uma amostra característica de determinada idade que se dá em cada geração.

\section{CONSIDERAÇÕES FINAIS}

A apreciação parcialmente dos dados trouxe à luz da obscuridade do conhecimento, relevantes informações para a sustentação de algumas conjecturas que orientarão nosso estudo sociolinguístico na comunidade observada. Não obstante, cabe notar que por se tratar de um estudo não concluído, isso por considerar limitado o número de falantes, o que por sua vez, na respectiva análise não respaldada de conclusões decisivas que venham apoiar hipóteses definitivas. Deste modo, esse estudo continua na busca de implicações mais incisivas, cujo objetivo é fornecer aos estudos variacionistas informações que possibilitem aos estudiosos de nosso objeto de pesquisa, uma melhor compreensão do fenômeno verificado.

Esperamos que após a realização desta pesquisa termos atingido o primeiro objetivo, visto que mostramos o fenômeno linguístico - do apagamento da plural concordância nominal na fala do maceioense, o qual varia sincronicamente. Além disso, foi possível demonstrar que o processo de oposição entre presença e ausência de marcas formais de plural nos elementos que se flexionam no sintagma nominal, se estabelece com uma lista de variáveis linguísticas e sociais.

Além disso, foi possível demonstrar que a variável de gênero, em nosso contexto, corrobora a teoria de que as mulheres usam mais norma de prestigio que os homens, haja vista que elas demonstram estarem mais propensas no uso das formas avaliadas mais "corretas" que os homens. E, que na fala da comunidade em estudo há uma tendência a uma mudança em progresso, a qual teve sua constatação pelo fato de os falantes mais jovens conservarem mais o plural da concordância nominal e os mais velhos apresentarem um índice maior de variação na fala. 


\section{REFERÊNCIAS}

BORTONI-RICARDO, S. M. Educação em língua materna: a sociolinguística na sala de aula. São Paulo: Parábola Editorial, 2004.

BAXTER, A, LUCCHESI, D. \& GUIMARÃES, M. Gender agreement as a decreolizing feature of the Afro-Brazilian rural dialect of Helvécia, em: Journal of Pidgin and Creole Language, 1997.

CARvalho, R. C. de. A Concordância de Número no Sintagma Nominal na Fala Urbana de Rio Branco. Campinas, SP: [s.n.], 1997.

CHAMBERS, J. K. \& TRUDGILL, P. Dialectology. Cambridge University Press. 1998.

LABOV. W. Principles of Linguistic Change, Internal Factors. Oxford/Cambridge: Blackwell, 1994.

LABOV, W. Padrões sociolinguísticos. São Paulo: Parábola Editorial. Tradução: Marcos Bagno, Maria Marta Pereira Scherre, Caroline Rodrigues Cardoso. 2008.

MONTEIRO, J.L. Para compreender LABOV. Rio de Janeiro: Vozes, 2000.

NARO, A. J..The social and structural dimensions of a syntacticchange. Language. LSA, 57(1):63-98. 1981.

SCHERRE, M. M. P. A regra de concordância de número no sintagma nominal em Português. Rio de Janeiro, PUC, 1978. Dissertação de Mestrado.

Reanálise da concordância nominal em português. Rio de Janeiro, 1988. Tese (Doutorado) - Universidade Federal do Rio de Janeiro

Aspectos da concordância de número no português do Brasil. Revista Internacional de Língua Portuguesa (R1LP). Norma e Variação do Português, v.12, p.37-49, 1994.

\& NARO, A. J. Sobre o deslocamento do controle da concordância verbal. Revista de lingüística (PPGL/UFRJ), v.3, p.133 -159, 2007.

SILVA, J. A. A et al. Concordância Verbal no Português Popular do Brasil: aspectos empírico-teóricos da concordância verbal na terceira pessoa do plural ou p6 na comunidade de fala de Vitória da Conquista. In: Jornada do Grupo de Estudos Linguísticos do Nordeste, 2012, Natal. Anais da Jornada do Grupo de Estudos Linguísticos e Literários do Nordeste. Natal: EDUFRN, 2012. v. 01. Disponível em: http://www.gelne.org.br/Site/arquivostrab/1157-Texto\%20\%20Danilo\%20da\%20Silva\%20Santos.pdf. 
WOlfram, W. A. A Sociolinguistic Discription Of Detroit Negro Speech. Center For Applied Linguistic. Massachusetts Avenue. Washington, D.C. 1969. 